Document downloaded from:

http://hdl.handle.net/10251/110346

This paper must be cited as:

Arévalo-Alquichire, S.; Ramírez, C.; Andrade, L.; Uscategui, Y.; Diaz, LE.; Gómez-Tejedor, JA.; Vallés Lluch, A.... (2018). Polyurethanes from modified castor oil and chitosan.

Synthesis, characterization, in vitro degradation, and cytotoxicity. Journal of Elastomers and Plastics. 50(5):419-434. doi:10.1177/0095244317729578

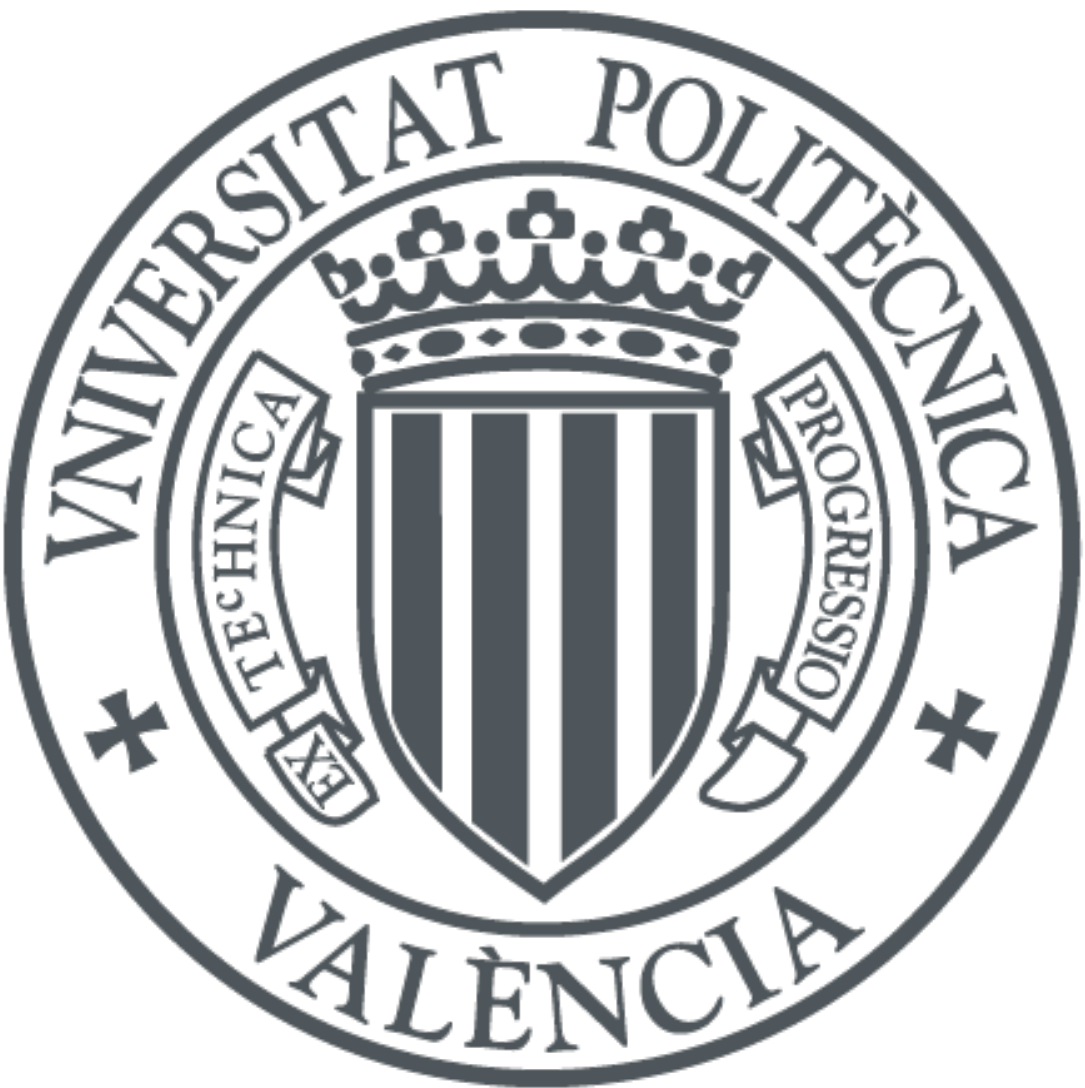

The final publication is available at

https://doi.org/10.1177/0095244317729578

Copyright SAGE Publications

Additional Information 


\section{Polyurethanes from castor oil and chitosan}

\section{as potential biomaterials: Synthesis,}

\section{characterization, in vitro degradation and}

\section{cytotoxicity}

Said J Arévaloํㅜ, Claudia Ramírez ${ }^{1}$, Laura Andrade ${ }^{1}$, Yomaira

Uscategui $^{1}$, Luis E Diaz² ${ }^{2}$ José A Gómez-Tejedor ${ }^{3}$, Ana Valles-

Lluch $^{3}$ and Manuel F Valero ${ }^{1}$

Journal of Elastomers and Plastics, 2017, 50(5): 419-434.

DOI: $\underline{10.1177 / 0095244317729578}$

${ }^{1}$ Energy, Materials and Environmental Group, GEMA, Universidad de La Sabana, Chia, Cundinamarca, Colombia

${ }^{2}$ Bioprospecting Research Group, GIBP, Universidad de La Sabana, Cundinamarca, Chia, Cundinamarca, Colombia

${ }^{3}$ Centre for Biomaterials and Tissue Engineering, CBIT, Universitat Politècnica de València, Valencia, Spain 
Journal of Elastomers and Plastics, 2017, 50(5): 419-434. DOI: $\underline{10.1177 / 0095244317729578}$

\section{Corresponding author:}

Manuel F. Valero, Universidad de La Sabana, Energy, Materials and Environment Group, Campus del Puente del Común, Km. 7, Autopista Norte de Bogotá. Chía, Cundinamarca, 250001, Colombia.

Email: manuel.valero@unisabana.edu.co

\section{Abstract}

The aim of this study was to evaluate the effect of polyol and chitosan (CS) incorporation within polyurethanes (PUs) and their resulting thermal stability, hardness, swelling behaviour, in vitro degradation, and cell viability to establish the potential for these materials in biomedical applications. CO (CO) was modified by a transesterification reaction with pentaerythritol. Original CO and modified CO, isophorone diisocyanate (IPDI) in a NCO/OH equal to 1, CS were used for PU synthesis. PUs were characterized by FTIR, hydroxyl value (ASTM D1957), thermogravimetric analysis, and Shore A hardness (ASTM D2240). The contact angle and swelling assay with PBS was carried out to study the hydrophilic character. Assays at $37^{\circ} \mathrm{C}$ and $105^{\circ} \mathrm{C}$ assessed in vitro degradation. Finally, the cell viability of a L-929 mouse embryo fibroblast was performed on solid polymers and degradation products. The hydroxyl value confirms CO modification, and IR analysis confirms CS incorporation into the matrix. The thermal assay does not show that new degradation stages and polyol, with a high functionality, had better mechanicals results due to the increase in crosslinking. The contact angle shows the hydrophobic surface with an angle over $65^{\circ}$, and the CS and polyol 
Journal of Elastomers and Plastics, 2017, 50(5): 419-434. DOI: $\underline{10.1177 / 0095244317729578}$

type do not effect swelling and in vitro degradation. The cell viability was over $70 \%$ in both cases, and solid polymers and degradation products involve non-cytotoxic effects on the samples. The results suggest a potential for these formulations in the biomedical field.

\section{Keywords}

Polyurethane, cytotoxicity, biomaterial, Castor oil, chitosan, transesterification

\section{Introduction}

Polyurethanes, a synthetic material, consist of repeated blocks of hard and soft segments that provide unique properties and a wide range of applications. Some properties include mechanical and chemical properties, controllable degradation, biostability, biocompatibility, haemocompatibility ${ }^{1}$ and chemical structure analogues of urethane bond and peptide bond of proteins, ${ }^{2}$ which make an outstanding material for medical applications. PU has a strong structure/properties relationship, therefore, chemical modifications of monomers and mixing with other materials is an alternative to improve a desired property. PUs with other polymers such as starch, cellulose, and chitin have been studied. ${ }^{3-5}$ Valero $^{6}$ studied the effects, particularly the properties and in-vitro degradation, of introducing starch into the PU. The results show an improvement of the properties with the addition of original starch (S) and acylated starch (SM) on PU. The interaction between SM and PU through hydrogen bonds improves thermal and mechanical properties but decreases the degradation rate resulting from the strong interaction between polymers; hydrogen bonds worked as a barrier for 
Journal of Elastomers and Plastics, 2017, 50(5): 419-434. DOI: $\underline{10.1177 / 0095244317729578}$

degradation. Macocinschi, D., et. al. ${ }^{7}$ synthetized a PU-extracellular matrix with bionanocomposites and a coating of biocompatible polymers and silver through solvent casting and electrospinning in order to improve antibacterial and biocompatibility properties for urinary catheters, and the increase in the amount of silver improved antibacterial performance against E. coli, S. typhymurium and L. monocytogenes.

Ricinoleic acid has one hydroxyl group and is the most abundant fatty acid in CO, ${ }^{8}$ which has been studied as a renewable source for PU synthesis. ${ }^{1,9-11}$ In the biomedical field, Valero \& Diaz ${ }^{12}$ developed a bio-adhesive type PU from CO and modified starch via glycosylation with ethylene glycol and lysine methyl ester diisocyanate. The results showed a decrease in mechanical and thermal properties, but they reported an increase in in vitro degradation and swelling behaviour. Additionally, the bio-adhesives had lower protein adhesion than materials from isophorone diisocyanate, lower cytotoxicity and good biocompatibility. Du, J., et. al. ${ }^{13}$ designed segmented aliphatic PUs based on glycerides of CO and isophorone diisocyanate with hydroxyapatite powder (HA). The incorporation of the HA and scaffold structure improved the mechanical performance and cytocompatibility and can provide a favourable 3D microenvironment for cells; this incorporation also and showed promising in vivo osteoneogenesis. Uscategui, Y., et. al. $^{14}$ studied the effect of polycaprolactone (PCL) incorporation in CO PUs over degradation, cytotoxicity and 
Journal of Elastomers and Plastics, 2017, 50(5): 419-434. DOI: $\underline{10.1177 / 0095244317729578}$

antibacterial activity; the results indicated that PUs synthetized with PCL have biocidal activity against Gram-negative bacteria and do not induce a cytotoxic effect.

Alternatively, chitosan is a heteropolysaccharide consisting of linear $\beta$-1,4-linked units and a de-N-acetylated analogue of chitin ${ }^{15}$. This allows the formation of an ionic complex with other natural and synthetic materials such as lipids, proteins and some polymers. Furthermore, amino and hydroxyl groups allow the formation of covalent bonds with other species. Similarly, many investigations reported antibacterial, antifungal, mucoadhesion, analgesic and haemostatic properties as well as non-cytotoxicity ${ }^{16-18}$. The application of chitosan in medicine has been studied in several ways including in haemostatic and wound healing dressing, ${ }^{19,20}$ bone tissue, ${ }^{21,22}$ skin tissue, ${ }^{23,24}$ cartilage tissue ${ }^{25,26}$ and drug delivery. ${ }^{18,27}$ Depan, D., et. al. $^{21}$ describe a study of a structure-processing-property relationship in nanocomposite scaffolds, which was based on grafted chitosan, for bone tissue engineering. Hydroxyl propylated chitosan linked with ethylene glycol functionalized nanohydroxyapatite was characterized by a highly porous structure and had significantly superior physio-chemical, mechanical and biological properties compared to pure chitosan. Biocompatible and supported adhesion, spreading, proliferation and viability of the osteoblasts cells suggest a promising approach of the structure in tissue engineering applications. Chen Y., et. al. ${ }^{28}$ developed a porous carboxymethyl chitosan grafted poly (acrylic acid) superabsorbent polymer through a novel solvent precipitation method. The 
Journal of Elastomers and Plastics, 2017, 50(5): 419-434. DOI: $\underline{10.1177 / 0095244317729578}$

results indicated that the modified polymer is non-cytotoxic and that it had high swelling capacity and better haemostatic performance in the treatments of the haemorrhage model of an ear artery, arteria cruralis and spleen of the New Zealand white rabbit than the unmodified polymer and other clinic wound dressings.

In this work, polymeric materials were synthesized from original CO (CO), modified CO (MCO) by a transesterification reaction with pentaerythritol (PE), and chitosan (CS), with the aim of relating their mechanical and swelling behaviour, in vitro degradation, and cytotoxicity with fibroblasts using the chemical structure of PUs to evaluate their potential as biomaterials.

\section{Materials and methods}

\section{Materials}

CO (Hydroxyl index: 163 mg KOH/g) USP grade was obtained from Químicos Campota (Colombia); pentaerythritol from Merck \& Co., Inc. (Germany), low molecular weight chitosan (75-85 \% deacetylate), isophorone diisocyanate, phosphate buffered saline, pH 7.4, and other analytical substances for characterization were obtained from Sigma Aldrich (USA). MTT (3-(4.5-Dimethylthiazol-2-yl)-2.5-Diphenyltetrazolium Bromide), RPMI (Roswell Park Memorial Institute) 1640 media, 2.5 \% Trypsin (10X), penicillin-streptomycin (Containing 10000 units/mL of penicillin and 10000 of streptomycin) from 
Journal of Elastomers and Plastics, 2017, 50(5): 419-434. DOI: $\underline{10.1177 / 0095244317729578}$

GIBCO/Invitrogen (UK); Foetal Bovine Serum (FBS) from Eurobio (France) and L929 mouse embryonic fibroblast were obtained from ATCC (USA).

\section{PU synthesis}

CO was modified by a transesterification reaction with pentaerythritol. $\mathrm{CO}$ was added into a 500-mL three-necked flat-bottomed flask, with a mechanical stirrer, reflux condenser, and temperature control. The reaction was heated to $120^{\circ} \mathrm{C}$ for 10 min to eliminate any trace of water, and then the temperature was increased to $180^{\circ} \mathrm{C}$ and $\mathrm{PbO}$ added $(0.05 \% \mathrm{wt})$ as the catalyst. The reaction was carried out for 2 hours with continuous stirring. Polyols and pentaerythritol concentrations are described in Table 1.

Table 1. Concentration of pentaerythritol for the synthesis of polyols.

\begin{tabular}{ll}
\hline Polyol Name & $\begin{array}{l}\text { PE concentration } \\
\text { (\% wt of PE/CO) }\end{array}$ \\
CO & 0 \\
P0 & 1.3 \\
P1 & 2.6 \\
\hline
\end{tabular}

After the transesterification reaction, each polyol was mixed with IPDI in a NCO/OH ratio equal to 1 with continuous stirring. Then, chitosan, at three different concentrations (2.5, 
Journal of Elastomers and Plastics, 2017, 50(5): 419-434. DOI: $\underline{10.1177 / 0095244317729578}$

5, and $7.5 \% \mathrm{wt}$ ), was added to reach a homogeneous phase. Before blending in the stainless steel mold, air was removed from the mix with a vacuum chamber until no more bubbles were observed. The polymer was cured at $105^{\circ} \mathrm{C}$ for 24 hours.

\section{Chemical, thermal, mechanical and morphological characterization}

To confirm the modification of CO with PE, a hydroxyl value assay was conducted according to ASTM D1957. Fourier transform infrared spectroscopy was recorded on a FTIR Thermo Scientific Nicolet iS10 in the range between $400 \mathrm{~cm}^{-1}$ to $4000 \mathrm{~cm}^{-1}$ to study the synthesis of urethane groups and chitosan incorporation.

The effect of polyol and CS over thermal and mechanical performance was studied with thermogravimetric assay (TGA) on a TGA/DSC Mettler Toledo STAR 1 System at a rate of $25^{\circ} \mathrm{C} / \mathrm{min}$ under an air atmosphere in the range of $25-600^{\circ} \mathrm{C}$, and the effect on hardness was assessed with shore A durometer (SHR-MARK-III) according to ASTM D2240.

Finally, the effect of CS on the surface was characterized by scanning electronic microscopy (SEM) with a PRO desktop microscope (Phenom, The Netherlands). Two magnifications were evaluated, 500× and 1500×. 
Journal of Elastomers and Plastics, 2017, 50(5): 419-434. DOI: $\underline{10.1177 / 0095244317729578}$

\section{In vitro degradation and swelling behaviour}

Degradation studies were executed with PBS. The dry weight of the samples (Wo) was recorded before they were incubated in degradation media for a fixed time. Assays was carried out at two temperatures, 37 and $105^{\circ} \mathrm{C}$. Samples were taken out from the medium, washed with distilled water, dried in a cooker at $60^{\circ} \mathrm{C}$ for 24 hours and weighed (Wt) at different time intervals. Degradation was quantified as the change in sample weight over time. The percentage of weight loss was estimated by

$$
\% \mathrm{wt} \mathrm{loss}=\frac{W o-W t}{W o} \times 100
$$

The swelling behaviour was measured by putting each sample in PBS at room temperature for specific time intervals, each sample was weighed after treatment (Wr). Water absorption was calculated by

$$
\% \text { swelling }=\frac{W r-W o}{W o} \times 100
$$

\section{Contact angle}

The contact angle of the polymers was performed with a drop shape analysis system (GH11, Kruss, Germany) using the sessile drop technique with distilled water at $20^{\circ} \mathrm{C}$. A series of 8 to 10 measurements was taken in each PU. 
Journal of Elastomers and Plastics, 2017, 50(5): 419-434. DOI: $\underline{10.1177 / 0095244317729578}$

\section{In vitro cell viability}

Solid polymers and degradation products (DP) were used for this assay. Solid pieces of polymers were cut and put in direct contact with cells, while DP was prepared by immersion of solid polymer in RPMI medium for $72 \mathrm{~h}$, then media was used for cell viability assay. Polymers were sterilized with UV radiation for 30 min for each size before cell culture. Polypropylene suture was used as positive control.

L929 (ATCC ® CCL-1) fibroblast was cultured in RPMI with 10\% of FBS (Fetal Bovine Serum) and 1\% of streptomycin-penicillin in a 96-well plate until 100\% confluence was achieved. The medium was changed for a non-supplemented one, and samples were put in direct contact with cells and media in the case of solid polymers, while $100 \mu \mathrm{L}$ was employed in the case of DP. Samples were incubated for $24 \mathrm{~h}$ at $37^{\circ} \mathrm{C}$ with $5 \%$ carbon dioxide. Then, $100 \mu \mathrm{L}$ of MTT (12 mM) was added in each plate and reacted for $4 \mathrm{~h}$ in an incubator. Next, MTT was removed, and $100 \mu \mathrm{L}$ of dimethylsulfoxide (DMSO) was added and incubated for 10 min. The optical density (OD) was measured with a well plate reader (BioTek ELx800). Cells without polymer or DP and non-supplemented media were used as a control. Cell viability was calculated according to the following equation:

$$
\% \text { Viability }=\frac{\mathrm{Abs}_{\text {sample }}}{\mathrm{Abs}_{\text {control }}} \times 100
$$


Journal of Elastomers and Plastics, 2017, 50(5): 419-434. DOI: $\underline{10.1177 / 0095244317729578}$

where $\mathrm{Abs}_{\text {sample }}$ is the OD of sample, and $\mathrm{Abs}_{\text {control }}$ is the OD of control plate.

\section{Statistical analysis}

The statistical differences of mean values were evaluated using one-way and two-way analysis of variance with the significance level $p<0.05$. Software SPSS V24 was employed.

\section{Results and discussions}

\section{Synthesis and physicochemical characterization}

MCO from the transesterification reaction of CO with pentaerythritol produced three polyols, and the hydroxyl value of each polyol can be seen in Figure 1. This property confirms the chemical modification of CO and a higher concentration of hydroxyl groups into polyols. Products from transesterification with PE was studied by Valero, M., et. al. ${ }^{29}$ through mass spectrometry, in which four main compounds were reported: ricinoleic monoglyceride,

ricinoleic diglyceride, pentaerythritol monoricinoleate and pentaerythritol diricinoleate ${ }^{30}$. A scheme of the reaction and composition of product can be observed in Figure 2a. 


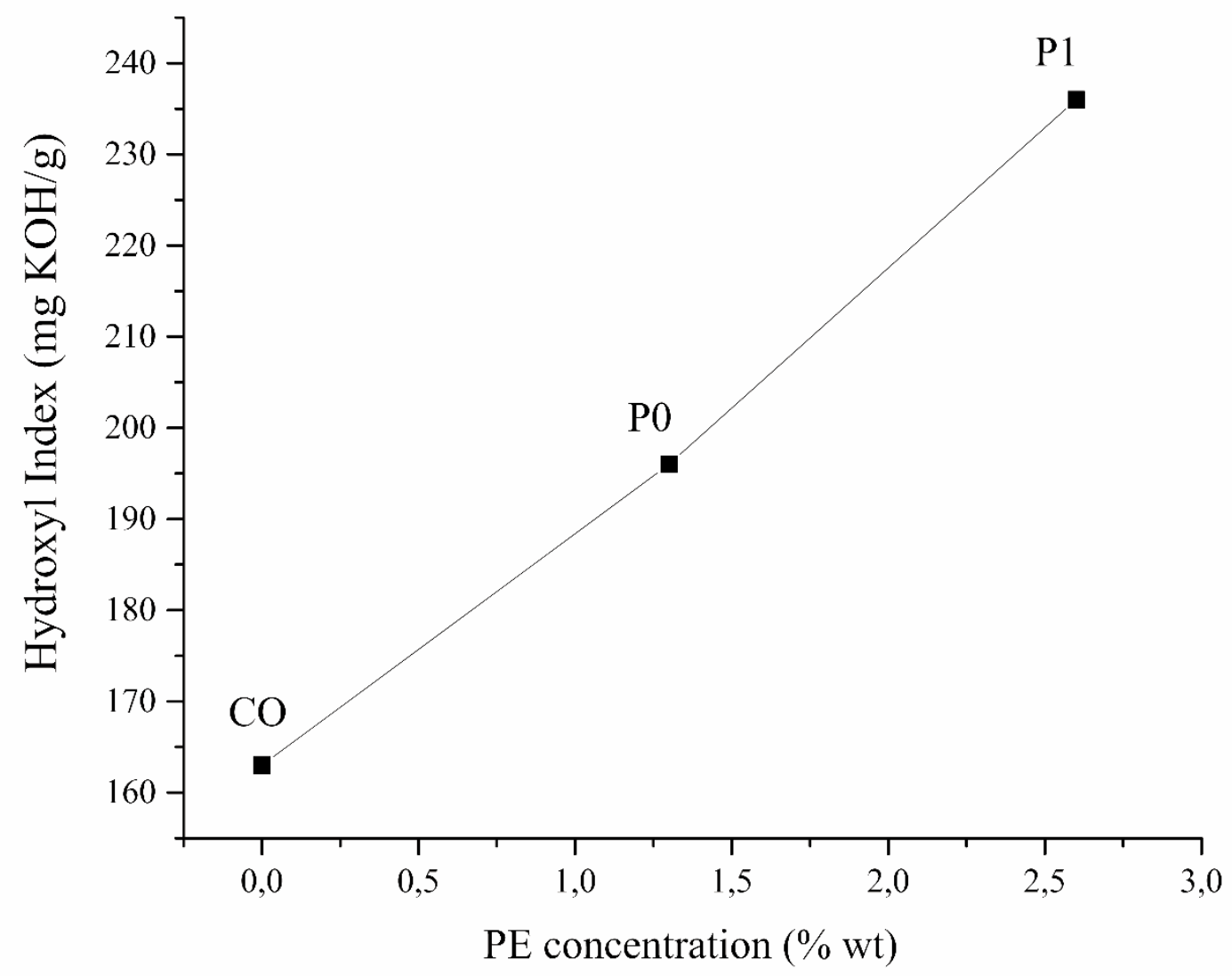

Figure 1. Hydroxyl values of polyols as a function of PE concentration.

Suspensions between CO, MCO and CS were made with external agitator. A specific amount of CS was added to each polyol, and they were mixed to reach a homogeneous phase; Table 2 shows the concentration of CS in each suspension. At curing times, suspensions with a high concentration of chitosan increased their viscosity due to particle dispersion. Additionally, a larger size of molecules in MCO than in CO increased the viscosity of the 
Journal of Elastomers and Plastics, 2017, 50(5): 419-434. DOI: $\underline{10.1177 / 0095244317729578}$

polyol. ${ }^{31}$ High concentrations of chitosan and the incompatibility of both polymers caused CS agglomeration and precipitation in some cases such as P1-CS7.5. Figure 2 shows a reaction scheme of the PU synthesis from the $\mathrm{CO}$ and transesterification reaction.

Table 2. Concentration and description of materials used in suspensions and PUs fabrication.

\begin{tabular}{|c|c|c|c|c|c|}
\hline Polyol & $\begin{array}{l}\text { CS } \\
\text { concentration } \\
(\% \text { of } \\
\text { CS/polyol) }\end{array}$ & $\begin{array}{l}\text { Suspension } \\
\text { name }\end{array}$ & $\begin{array}{l}\mathrm{NCO} / \mathrm{OH} \\
\text { ratio* }\end{array}$ & PU name & $\begin{array}{l}\text { Series } \\
\text { name }\end{array}$ \\
\hline \multirow{4}{*}{$\mathrm{CO}$} & 0 & $\mathrm{CO}$ & 1 & PU-CO & \multirow{4}{*}{ Series I } \\
\hline & 2.5 & CO-CS2.5 & 1 & PU-CO-CS2.5 & \\
\hline & 5 & CO-CS5 & 1 & PU-CO-CS5 & \\
\hline & 7.5 & CO-CS7.5 & 1 & PU-CO-CS7.5 & \\
\hline \multirow{4}{*}{ P0 } & 0 & P0 & 1 & PU-P0 & \multirow{4}{*}{ Series II } \\
\hline & 2.5 & P0-CS2.5 & 1 & PU-P0-CS2.5 & \\
\hline & 5 & P0-CS5 & 1 & PU-P0-CS5 & \\
\hline & 7.5 & P0-CS7.5 & 1 & PU-P0-CS7.5 & \\
\hline \multirow{4}{*}{ P1 } & 0 & $\mathrm{P} 1$ & 1 & PU-P1 & \multirow{4}{*}{ Series III } \\
\hline & 2.5 & P1-CS2.5 & 1 & PU-P1-CS2.5 & \\
\hline & 5 & P1-CS5 & 1 & PU-P1-CS5 & \\
\hline & 7.5 & P1-CS7.5 & 1 & PU-P1-CS7.5 & \\
\hline
\end{tabular}

*NCO/OH ratio used to calculate the amount of IPDI requirement for synthesis of PUs. 
(a)
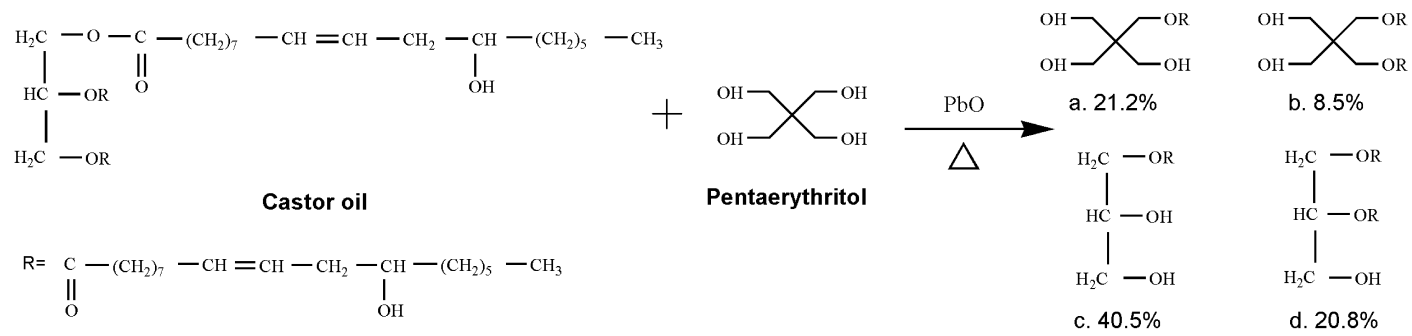

(b)

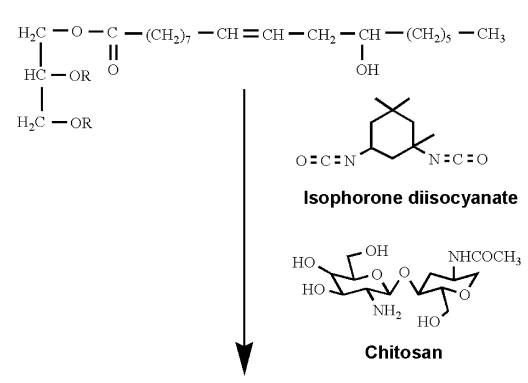

(c)
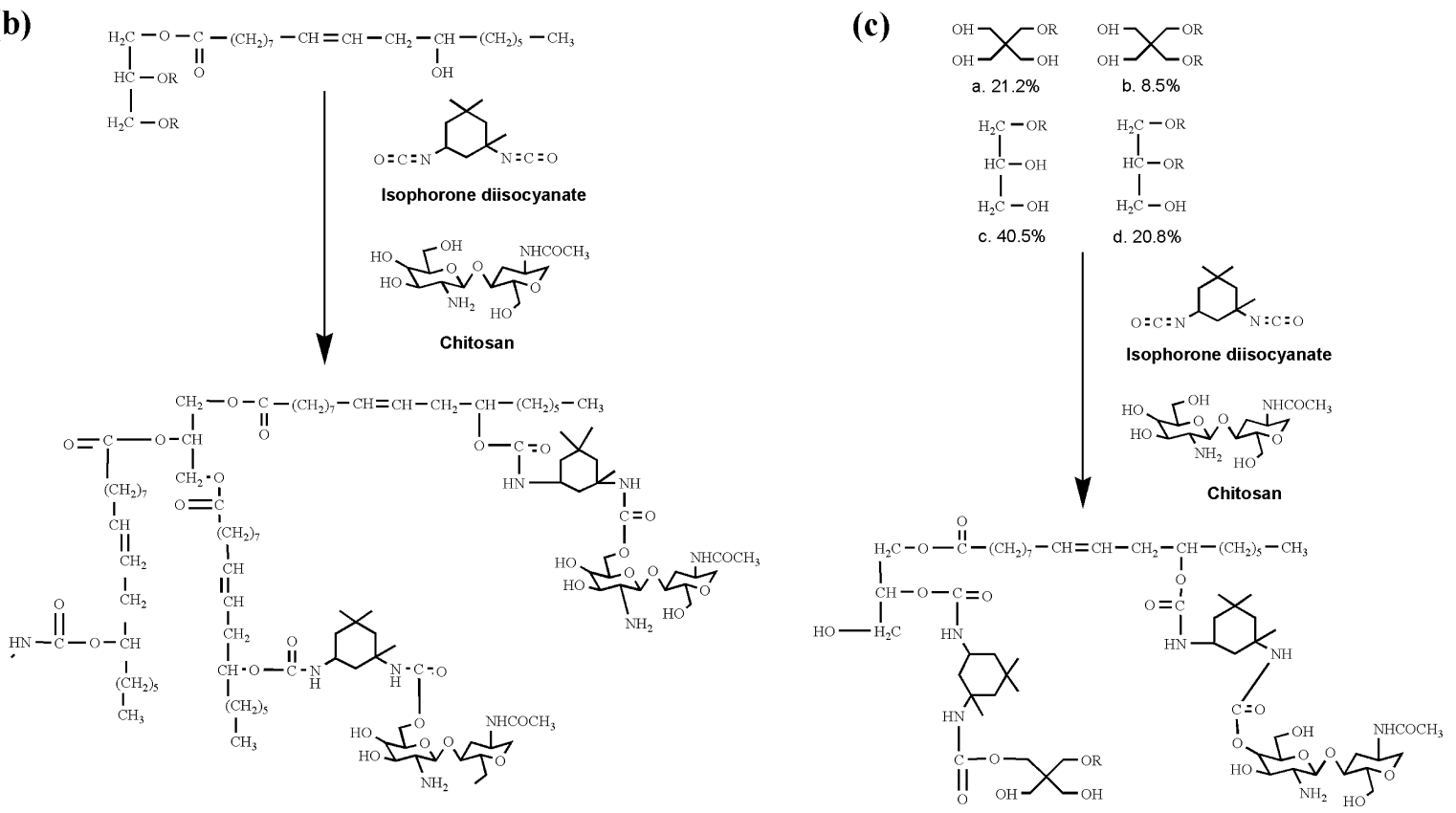

Figure 2. Scheme of reactions (a) Transesterification reaction of CO with PE, (b) PUs synthesis from CO, IPDI and CS, (c) Pus synthesis from products of transesterification reaction, IPDI and CS.

Infrared spectrums are shown in Figure 3, and spectrum from PU-CO have the typical absorption peaks assigned to PUs at 3400 and $1324 \mathrm{~cm}^{-1}$, which correspond to N-H and C$\mathrm{N}$, respectively, from the urethane bond. Additionally, at $1750 \mathrm{~cm}^{-1}$, the $\mathrm{C}=\mathrm{O}$ stretch was 
Journal of Elastomers and Plastics, 2017, 50(5): 419-434. DOI: $\underline{10.1177 / 0095244317729578}$

identified. Furthermore, asymmetric and symmetric stretching of - $\mathrm{CH}_{2}$ - present at 2912 and $2840 \mathrm{~cm}^{-1}$, , $^{2,32}$ respectively. The FTIR spectrum of PU-P1 show similar peaks of functional groups similar to PU-P, but at approximately 3260 and above $3500 \mathrm{~cm}^{-1}$, they identify that intermolecular hydrogen bonded $\mathrm{OH}$ due to the increase of functionality of polyol from the transesterification reaction. ${ }^{32}$

In the case of CS, the N-H band appeared at $3480 \mathrm{~cm}^{-1}$, and the C-N stretch appeared at $1324 \mathrm{~cm}^{-1}$. Amine I and amide II from partial N-deacetylation of chitin appeared at 1650 and $1590 \mathrm{~cm}^{-1}$, respectively, and a peak at $1400 \mathrm{~cm}^{-1}$ corresponds to $\mathrm{CH}_{3}$ symmetrical deformation, while a peak at $1150 \mathrm{~cm}^{-1}$ represents the C-O-C stretch. ${ }^{21}$ In PU-P-CS2.5, new bands appear in contrast with PU-CO; at $1690 \mathrm{~cm}^{-1}$, the presence of amine I is from CS. At approximately $3200 \mathrm{~cm}^{-1}$ and above $3500 \mathrm{~cm}^{-1}$, the peaks from the intermolecular hydrogen bonded $\mathrm{OH}$ as a result of the increase in the interaction between hydroxyl groups from the chitosan and functional groups of PU. This finding confirms the incorporation of CS into polyols and formation of the urethane bond $\left(1750 \mathrm{~cm}^{-1}\right)$. 
Journal of Elastomers and Plastics, 2017, 50(5): 419-434. DOI: $\underline{10.1177 / 0095244317729578}$

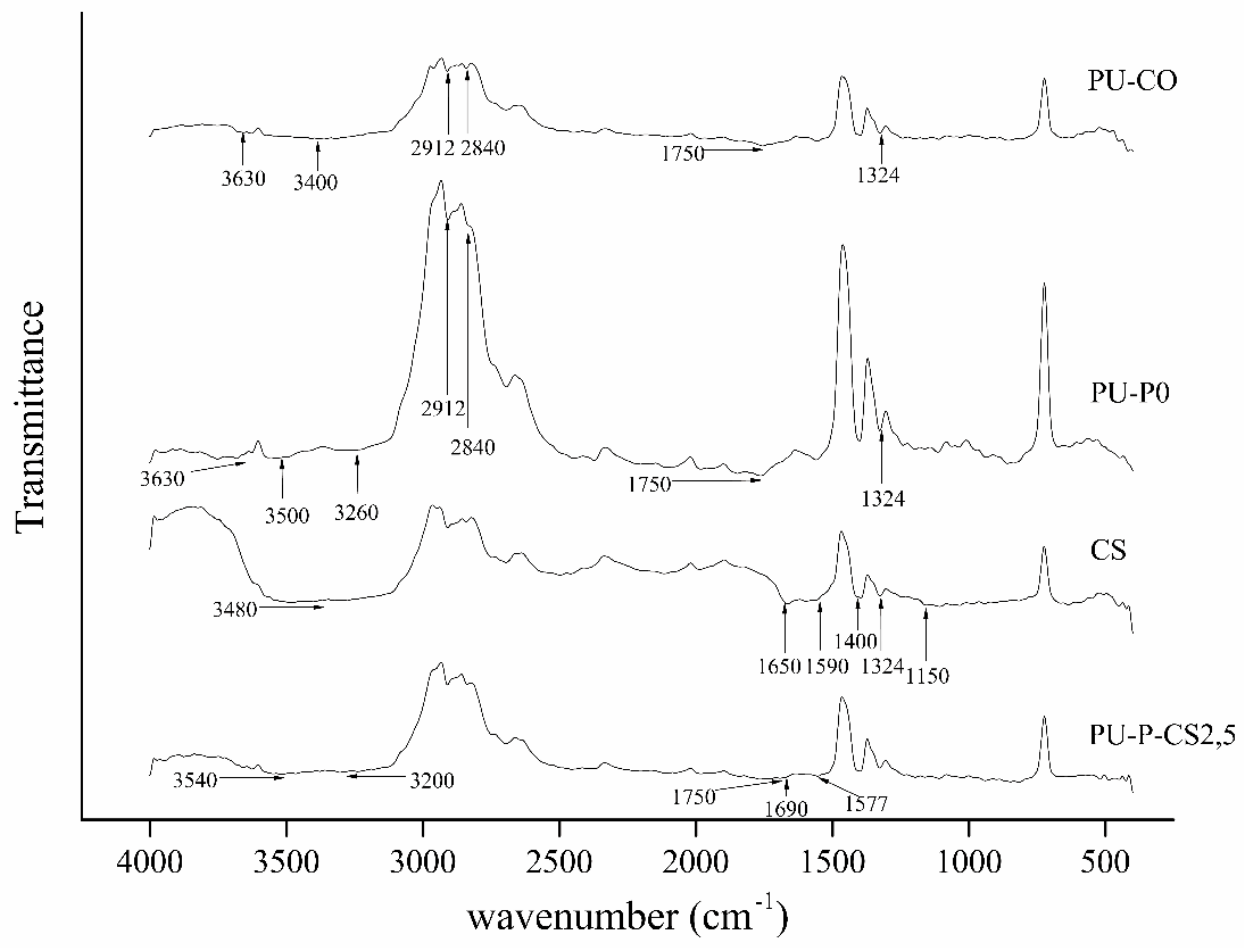

Figure 3. Infrared spectra of some PUs and chitosan.

\section{Thermal, hardness and morphological characterization}

From thermogravimetric analysis, all polymers were thermally stable under $275^{\circ} \mathrm{C}$. At least three stages were identified in the curve (Figure 4). The first stage, which occurred at approximately $280^{\circ} \mathrm{C}$ and $380^{\circ} \mathrm{C}$, corresponds to the hard segment (urethane bonds) of PUs. In the second stage, which occurred at the upper $380^{\circ} \mathrm{C}$ until approximately $420^{\circ} \mathrm{C}$, represents the soft segment ( $\mathrm{CO}$ fatty acid chain), and finally, the third stage corresponds to the 
Journal of Elastomers and Plastics, 2017, 50(5): 419-434. DOI: $\underline{10.1177 / 0095244317729578}$

unreactive residue of diisocyanate, in which those results are consistent with Valero, M. \& Diaz, L. ${ }^{33}$
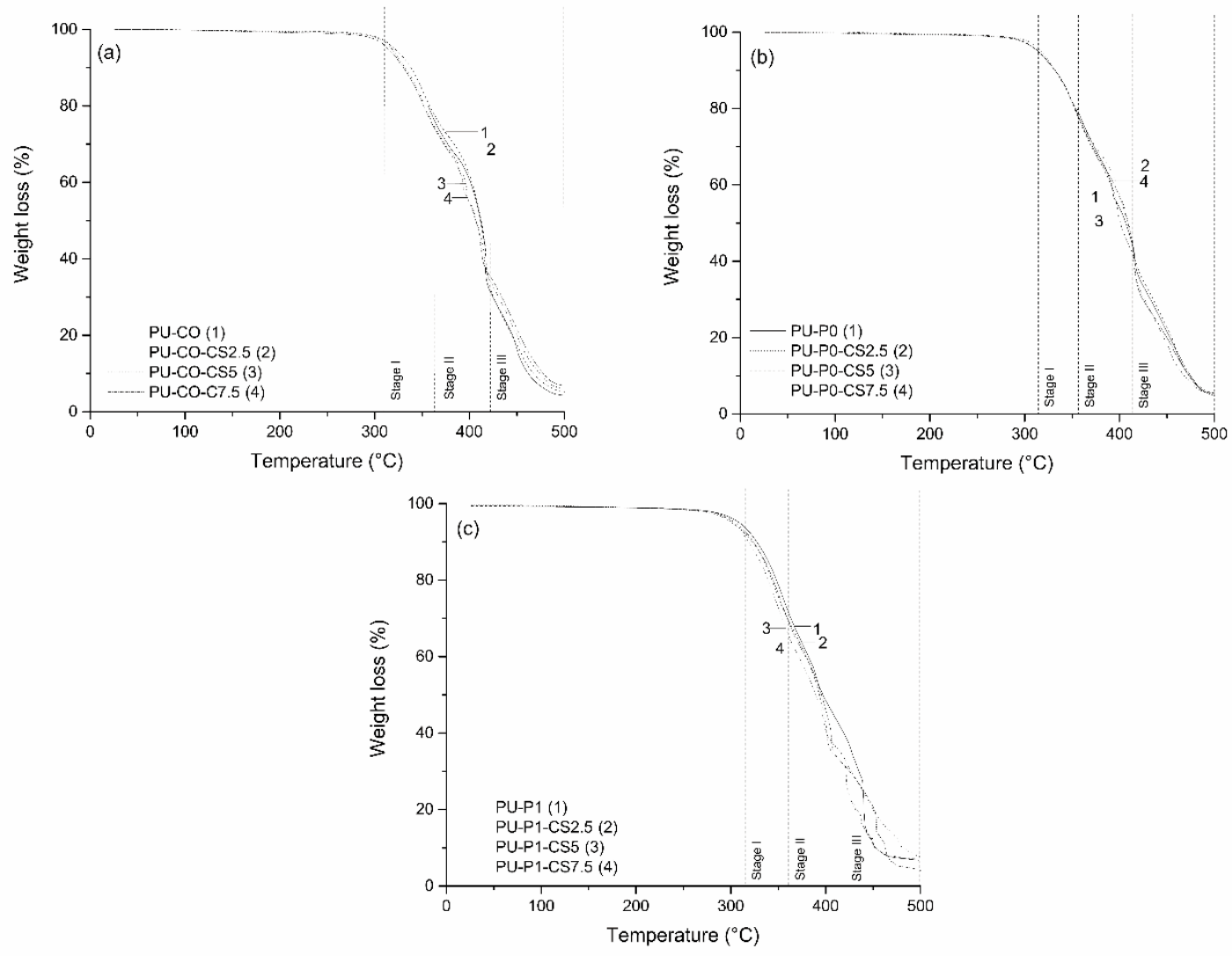

Figure 4. Thermograph from PUs under air atmosphere: (a) Series I: PUs from CO polyol, (b) Series II: PUs from P0 polyol, (c) Series III: PUs from P1 polyol.

Martinez, A.P, et. al. ${ }^{34}$ conducted a studied of the thermal degradation of chitosan in TGA under air atmosphere, in which they described three stages of degradation. The first 
Journal of Elastomers and Plastics, 2017, 50(5): 419-434. DOI: $\underline{10.1177 / 0095244317729578}$

stage, between $135^{\circ} \mathrm{C}$ and $300^{\circ} \mathrm{C}$, related to the decomposition of amine units, the next stage is the degradation of $-\mathrm{CH}_{2} \mathrm{OH}$ group, which starts at $300^{\circ} \mathrm{C}$ and continues up to $400^{\circ} \mathrm{C}$, and the end stage is the degradation of chitosan ring. In the case of PUs with CS, thermal degradation has a similar behaviour to PU without CS. Those polymers miss the stage before $320^{\circ} \mathrm{C}$, which is a result of the matrix-filler structure where CS is trapped into PU chains; this may cause an isolation effect that retards CS degradation until the first decomposition of PU takes place. The $-\mathrm{CH}_{2} \mathrm{OH}$ group and fatty acid chain have similar degradation temperatures, therefore, their decomposition overlaps in a similar method as the isocyanate residues and chitosan ring.

Some parameters of the TGA results are listed in Table 3. Samples showed lower values of onset temperature with the increase of CS than PUs without it, which means that the degradation steps of chitosan displacement are to the left of the first stage of PUs. The onset values are comparable with the results of some rigid modified CO foams described by Zhang, M., et. al. ${ }^{35}$ Similar behaviour was observed in temperatures of 50\% weight loss, in which the degradation of similar groups of polyols and CS results in a minimal reduction of temperature. The residue product at $500^{\circ} \mathrm{C}$ increases with the amount of chitosan, with the final step of CS degradation involving its carbon ring, where a higher concentration results in more product at the end of the assay. In the case of PUs of Series III, phase separation between polymers could modify the stages due to simultaneous degradation. 
Journal of Elastomers and Plastics, 2017, 50(5): 419-434. DOI: $\underline{10.1177 / 0095244317729578}$

Table 3. Onset temperature, temperature of $50 \%$ weight loss and weight percentage of residue at $500^{\circ} \mathrm{C}$.

\begin{tabular}{|c|c|c|c|c|}
\hline & & $\begin{array}{l}\text { Onset } \\
\text { temperature }\end{array}$ & $\begin{array}{l}50 \% \text { Weight loss } \\
\text { temperature }\end{array}$ & Residue (\% wt) \\
\hline \multirow[t]{4}{*}{ Series I } & PU-P & 307.5 & 394.4 & 3.981 \\
\hline & PU-P-CS2.5 & 301.3 & 393.7 & 4.975 \\
\hline & PU-P-CS5 & 299.1 & 392.2 & 5.471 \\
\hline & PU-P-CS7.5 & 292.2 & 391.7 & 6.195 \\
\hline \multirow[t]{4}{*}{ Series II } & PU-P0 & 298.8 & 392.3 & 4.414 \\
\hline & PU-P0-CS2.5 & 299.4 & 393.9 & 5.023 \\
\hline & PU-P0-CS5 & 294.6 & 393.5 & 5.135 \\
\hline & PU-P0-CS7.5 & 292.9 & 392.9 & 5.260 \\
\hline \multirow[t]{4}{*}{ Series III } & PU-P1 & 293.3 & 391.1 & 5.654 \\
\hline & PU-P1-CS2.5 & 274.9 & 381.2 & 1.475 \\
\hline & PU-P1-CS5 & 267.8 & 380.4 & 7.356 \\
\hline & PU-P1-CS7.5 & 279.0 & 384.1 & 3.978 \\
\hline
\end{tabular}

*Mass residue at $500^{\circ} \mathrm{C}$

In the mechanical assay, the effect of hydroxyl value and chitosan concentration was studied. Statistics showed significant differences between the series due to polyol functionality. In Table 4, the hardness of the polymers from P1 (Highest hydroxyl value) results in a greater property response in comparison with their analogue. Valero, M., et. al. ${ }^{30}$ described the behaviour of PU from CO modified with PE and glycerol, and in both cases, mechanical properties of materials obtain a high level with the rise of modifier agent due to an increase in crosslinking. Therefore, in our case, an increase between intermolecular forces in PUs can be concluded. Additionally, ANOVA showed statistical differences among CS 
Journal of Elastomers and Plastics, 2017, 50(5): 419-434. DOI: $\underline{10.1177 / 0095244317729578}$

concentrations, and a decrease trend can be observe in Table 3. This should be caused by enhancement of the amorphous phase, in which addition of CS during polymerization could restrict the chain arrangements and high concentrations of CS and incompatibility can generate phase separation avoiding filler function.

Table 4. Shore A Hardness of different types of PUs.

\begin{tabular}{lll}
\hline & PU & $\begin{array}{l}\text { Hardness } \\
\text { (Shore A) }\end{array}$ \\
\hline \multirow{2}{*}{ Series I } & PU-P & 63.2 \\
& PU-P-CS5 & 45.0 \\
& PU-P-CS7.5 & 50.8 \\
\hline \multirow{5}{*}{ Series II } & PU-P0 & 55.6 \\
& PU-P0-CS2.5 & 59.3 \\
& PU-P0-CS5 & 61.7 \\
& PU-P0-CS7.5 & 64.9 \\
\hline \multirow{5}{*}{ Series III } & PU-P1 & 92.0 \\
& PU-P1-CS2.5 & 81.9 \\
& PU-P1-CS5 & 83.9 \\
& PU-P1-CS7.5 & 81.3 \\
\hline
\end{tabular}




\section{CS concentration}

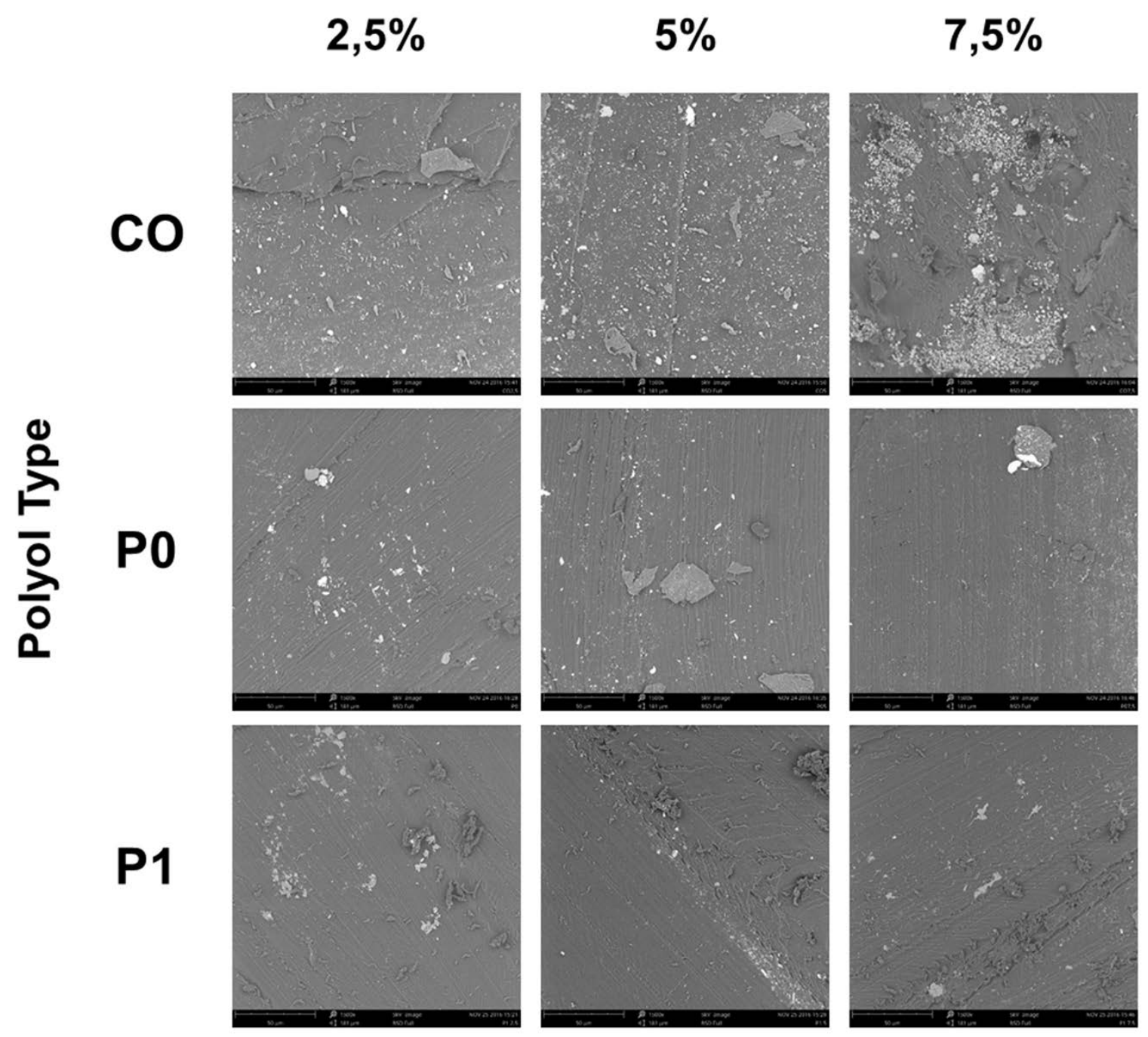

Figure 5. SEM images from polyurethanes of CO, P0, P1 and different concentration of chitosan 
Journal of Elastomers and Plastics, 2017, 50(5): 419-434. DOI: $\underline{10.1177 / 0095244317729578}$

SEM micrograph are presented in Figure 5. It shows that increase of CS concentration, enhance face separation since agglomeration of chitosan can observed. In the case of CO, presented small granules of CS and organization in microphases. It could explain the reduction in some properties of the materials. In the same way, PUs from P0 and P1 presented CS granules but bigger in these cases. High viscosity of P0 and P1 difficult homogenous phase during mixing process. So it logic found it. Also as CO, we can observe phase separation.

\section{Swelling behaviour and in vitro degradation}

Statistical testing of swelling and in vitro degradation demonstrated no significant differences between series (Polyol type) and CS concentration. Swelling is directly related to the solution of the polymer in the solvent at a higher similarity of the chemical structure of both; the solubility will be greater. The similarity of the chemical structure between polymer and medium is low since the PBS solvent is an aqueous solution (polar) and polymers are based on CO (hydrophobic); thus, a low absorption will be expected. The mechanism of swelling begin as the medium diffuses inside polymers and reduces intermolecular forces (Hydrogen bonds). ${ }^{36}$

The maximum water intake is described in Figure 5, in which the incorporation of CS decreases the retention in most cases. The filler function of CS enhances the crosslinking 
Journal of Elastomers and Plastics, 2017, 50(5): 419-434. DOI: $\underline{10.1177 / 0095244317729578}$

density and restricts the chains movement. Zia KM., et. al. ${ }^{37}$ demonstrated that based on chitin-HPTB (hydroxyl terminated polybutadiene), PU materials reduce their water absorption with the increase of chitin content in the samples, while PU synthesized samples without chitin showed greater swelling due to a higher degree of crosslinking between PU and chitin. Time depended analysis of this property shows initial water absorption until day 5, after which a decrease trend and later stabilization lead to a degradation process. Those results indicate that swelling character relates with the nature of polymers, as mentioned above, and that the mechanism starts with a diffusion of water to the material bulk.

The contact angle of polymers show an increasing trend with the incorporation of CS; the values did not show statistical differences between polyols groups but CS affect surface response. In series I, concentration of $2.5 \%$ have greater value than others. Also series III, have large value in the same concentration. Significant differences was found between CS proportions into polymers. The PUs described have contact angle up to $70^{\circ}$ (See Figure 6) which can promote cell adhesion, since materials with angles in the range of $40^{\circ}$ and $80^{\circ}$ have good affinity for supporting cell growth. ${ }^{38}$ Previous studies with lower CS amount presented a decreasing of contact angle due to interaction of hydrophilic groups of $\mathrm{CS}^{39}$. In our case agglomeration could restring functional groups interactions. Hydrophobic surfaces reduce the interaction with water, consequently, it works as a barrier for diffusion with crosslinking. 
Journal of Elastomers and Plastics, 2017, 50(5): 419-434. DOI: $\underline{10.1177 / 0095244317729578}$

Additionally, a time-dependent study of degradation was conducted. The process starts with an increase of weight due to initial water retention and later, to the weight loss step. The primary steps of polymer degradation involve the diffusion of water into spaces of macromolecules that acts as a plasticizer and that make the material more ductile. After that, chain scission takes place through hydrolysis, in which water molecules may facilitate the cleavage of some bonds such as urethane and hemiacetal. Low water absorption, as described above, is related with the low degradation of materials. ${ }^{36}$ High functionality polymers (Series III) had lower results than these analogues due to a larger secondary interaction. In some cases, they acquired weight by water accumulation and very poor degradation. No significance difference was found between series and CS concentration. Both phenomena, degradation and swelling, take place simultaneously.

In a similar fashion, degradation at $105^{\circ} \mathrm{C}$ was measured for $72 \mathrm{~h}$. The results show no difference with the factors (Polyol type and CS concentration), which is in agreement with the results at $37^{\circ} \mathrm{C}$. Additionally, polymers with high functionality had lower values of degradation, and incorporation of CS reduced the degradation due to the possible enhancement of crosslinking (see Figure 5). This outcome means that the same phenomena are happening in both tests. A comparison of results from both temperatures show significance differences. At high temperature degradation increased; It is possible that temperature stimulate chain cleavage. 

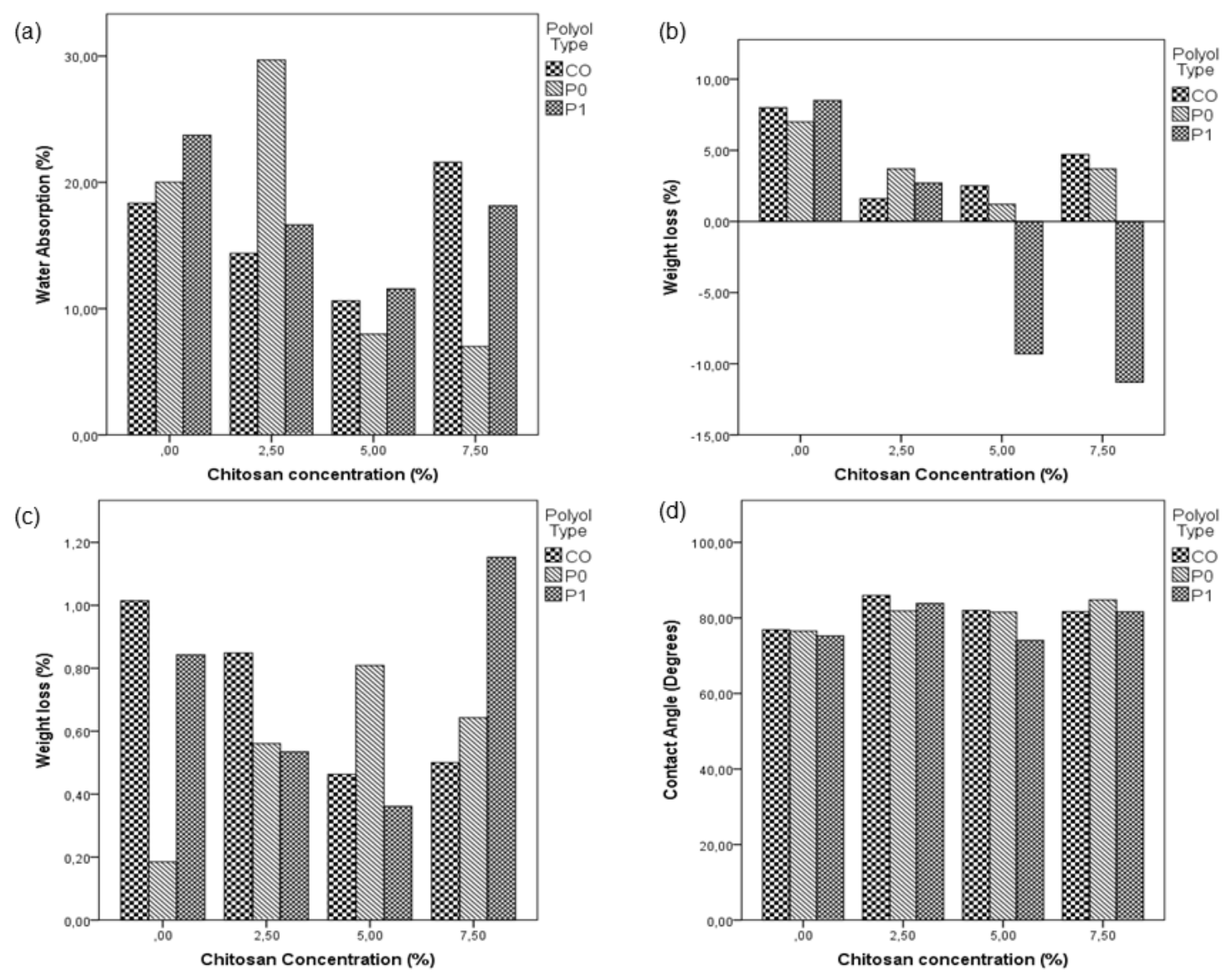

Figure 6. Swelling, degradation and contact angle: (a) Maximum water retention of polyurethanes; (b) Degradation of PUs at $37^{\circ} \mathrm{C}$; (c) Degradation of PUs at $105^{\circ} \mathrm{C}$; (d) Contact angle of Pus 
Journal of Elastomers and Plastics, 2017, 50(5): 419-434. DOI: $\underline{10.1177 / 0095244317729578}$

\section{Cell viability}

The cell viability of polymers was tested with L-929 fibroblast. The results of direct contact (Solid polymers) show an improvement of viability with the increase of chitosan into the matrix (See Figure 7). All samples obtained cell viability over 70\%. No significance differences between control and PUs from series II and III was found, analysis of chitosan show that concentration of $2.5 \%$ increase cell viability in contrast with PU-P0 and there aren't difference with highest concentration., which suggest that PUs do not generate a toxic effect on the fibroblast. Furthermore, the contact angle and cell viability have similar behaviour, in which an increase of the contact angle represents better viability. Hydrophobic surfaces have been reported as being characteristic for good cell adhesion. Suture of polypropylene (SPP) was used as a biomaterial positive control, and the results have statistical differences with

samples. Uscategui, Y., et. al. ${ }^{14}$ evaluated PUs from CO, different concentration of poly $(\varepsilon-$ caprolactone), and IPDI over L-929 fibroblast, where the viability was between 70-140\%. The PCL concentration between 0 and 10\%, which did not affect cell viability but highly reduced it. 

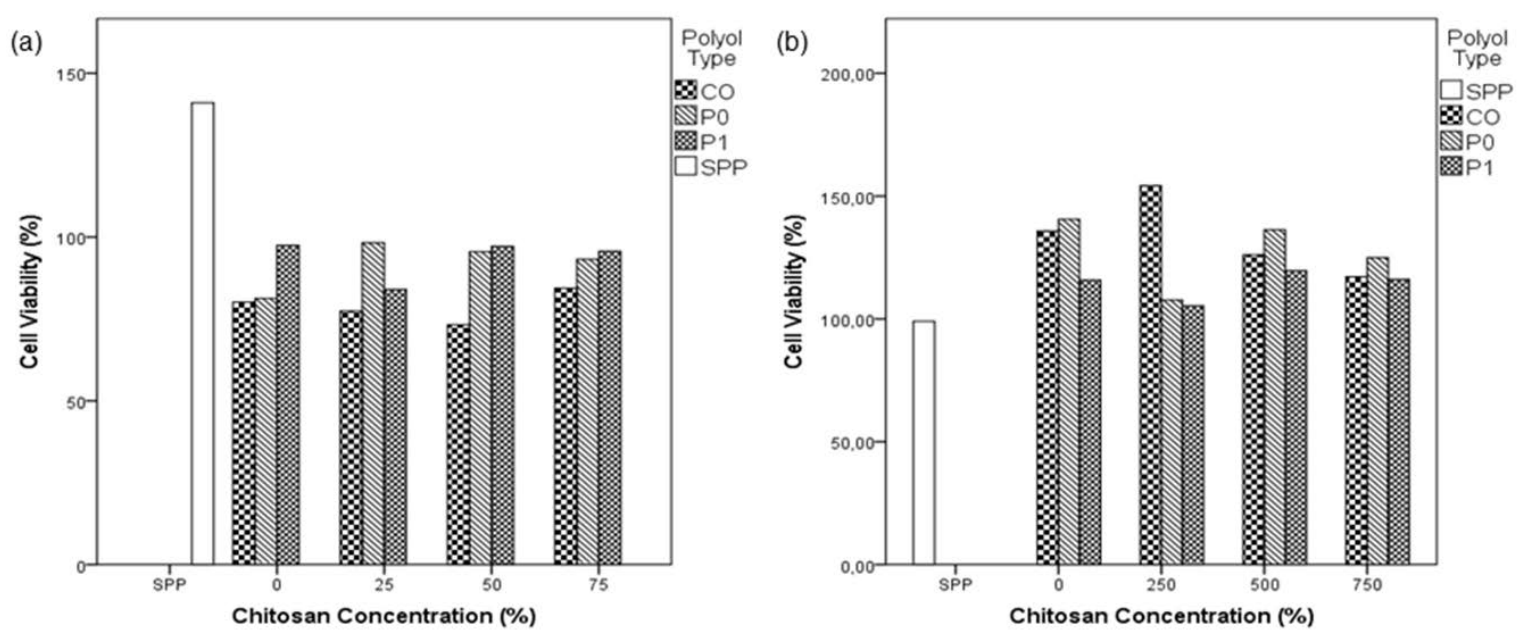

Figure 7. Cell viability of L-929 in contact with: (a) solid polymers, (b) Degradation products.

The DP of PUs were studied in L-929. In this case, all samples had values of viability higher than $100 \%$, which means that no toxic effect was identified in degradation products, a finding that is similar for solid polymers. Further, no statistical effect was observed with the polyol type and CS concentration factors. The results of cell viability show no cytotoxic phenomena of polymers, therefore, these samples could be used as biomaterials.

\section{Conclusion}

A study of physicochemical properties, hardness, in vitro degradation, and cell viability was conducted for PUs synthetized from CO, chitosan and IPDI. Polymers were studied by FTIR, and CS incorporation and chemical modification of CO were identified. Samples are 
Journal of Elastomers and Plastics, 2017, 50(5): 419-434. DOI: $\underline{10.1177 / 0095244317729578}$

thermally stable below $275^{\circ} \mathrm{C}$, and the same degradation steps were shown at different CS concentrations, which means that CS was trapped into the polyol matrix. Polyols with high functionality had better hardness properties due to the increase of crosslinking, in which swelling and in vitro degradation reduce because of the larger secondary interaction. Polymers without CS had higher results than their analogue with CS. The evaluation of cytotoxicity on L-929 revealed that PUs have greater viability than 70\% (solid polymers and degradation products or extracts). PUs assessed in this research were physicochemical, swelling and biological properties that showed potential in medical applications such as sutures or wound healing.

\section{Acknowledgements}

The authors are specially grateful with the engineering faculty of Universidad de La Sabana for all the resources and support in this research. CIBER-BBN is an initiative funded by the VI National R\&D\&I Plan 2008-2011, Iniciativa Ingenio 2010, Consolider Program. CIBER Actions are financed by the Instituto de Salud Carlos III with assistance from the European Regional Development Fund.

\section{Declaration of conflicting interests}

The authors declared no potential conflicts of interest with respect to the research, authorship, and/or publication of this article. 
Journal of Elastomers and Plastics, 2017, 50(5): 419-434. DOI: $\underline{10.1177 / 0095244317729578}$

\section{Funding}

The author(s) disclosed receipt of the following financial support for the research, authorship, and/or publication of this article: This work was supported by Universidad de La Sabana under grant number ING-160-2015. Also, Jose’ A. Go'mez-Tejedor and Ana Valle's-Lluch acknowledge the support of the Spanish Ministry of Economy and Competitiveness (MINECO) through the project DPI2015-65401-C3-2-R (including the FEDER financial support).

\section{References}

1. Ganji Y, Kasra M, Salahshour KS, et al. Synthesis and characterization of gold nanotube/nanowire-PU composite based on CO and polyethylene glycol. Mater Sci Eng C Mater Biol Appl 2014; 42: 341-349.

2. Zia KM, Zuber M, Bhatti IA, et al. Evaluation of biocompatibility and mechanical behavior of PU elastomers based on chitin/1,4-butane diol blends. Int J Biol Macromol 2009; 44: 18-22.

3. Kucinska-Lipka J, Gubanska I, Janik H, et al. Fabrication of PU and PU based composite fibres by the electrospinning technique for soft tissue engineering of cardiovascular system. Mater Sci Eng C Mater Biol Appl 2015; 46: 166-176.

4. Fu H, Wang Y, Chen W, et al. Reinforcement of waterborne PU with chitosan-modified halloysite nanotubes. Appl Surf Sci 2015; 346: 372-378. 
Journal of Elastomers and Plastics, 2017, 50(5): 419-434. DOI: $\underline{10.1177 / 0095244317729578}$

5. Usman A, Zia KM, Zuber M, et al. Chitin and chitosan based PUs: a review of recent advances and prospective biomedical applications. Int J Biol Macromol 2016; 86: 630_ 645.

6. Valero VMF. Degradación in-vitro de mezclas de poliuretano termoplástico y almidón modificado. Polímeros Ciência e Tecnol 2013; 23: 373-382.

7. Macocinschi D, Filip D, Paslaru E, et al. PU-extracellular matrix/silver bionanocomposites for urinary catheters. J Bioact Compat Polym 2015; 30: 99-113.

8. Miao S, Wang $\mathrm{P}, \mathrm{Su} \mathrm{Z}$, et al. Vegetable-oil-based polymers as future polymeric biomaterials. Acta Biomater 2014; 10: 1692-1704.

9. Valero MF and Gonzalez A. PU adhesive system from CO modified by a transesterification reaction. J Elastomers Plast 2012; 44: 433-442.

10. Mazo P, Rios LA, Restrepo G. Síntesis de poli ácido láctico y poli ricinoleato empleando calentamiento por microondas y su utilización en la producción de termoplasticos de poliuretano. Polímeros 2011; 21: 83-89.

11. Ferreira P, Pereira R, Coelho JFJ, et al. Modification of the biopolymer CO with free isocyanate groups to be applied as bioadhesive. Int J Biol Macromol 2007; 40: 144-152.

12. Valero MF. Bioadhesivos tipo poliuretano obtenidos a partir de polioles derivados de aceite de higuerilla y almidón modificado candidatos en aplicaciones biomédicas. Rev Lat Met Mat 2016; 36: 9-19. 
Journal of Elastomers and Plastics, 2017, 50(5): 419-434. DOI: $\underline{10.1177 / 0095244317729578}$

13. Du J, Zou Q, Zuo Y, et al. Cytocompatibility and osteogenesis evaluation of HA/GCPU composite as scaffolds for bone tissue engineering. Int J Surg 2014; 12: 404-407.

14. Uscátegui YL, Arévalo FR, Díaz LE, et al. Microbial degradation, cytotoxicity and antibacterial activity of PUs based on modified CO and polycaprolactone. $J$ Biomater Sci Polym Ed 2016; 27: 1860-1879.

15. Anitha A, Sowmya S, Kumar PTS, et al. Chitin and chitosan in selected biomedical applications. Prog Polym Sci 2014; 39: 1644-1667.

16. Croisier F, Jérôme C. Chitosan-based biomaterials for tissue engineering. Eur Polym J 2013; 49: 780-792.

17. Kim IY, Seo SJ, Moon HS, et al. Chitosan and its derivatives for tissue engineering applications. Biotechnol Adv 2008; 26: 1-21.

18. Dash M, Chiellini F, Ottenbrite RM, et al. Chitosan-A versatile semi-synthetic polymer in biomedical applications. Prog Polym Sci 2011; 36: 981-1014.

19. Lan G, Lu B, Wang T, et al. Chitosan/gelatin composite sponge is an absorbable surgical hemostatic agent. Colloids Surf B Biointerfaces 2015; 136: 1026-1034.

20. Jayakumar R, Prabaharan M, Sudheesh KPT, et al. Biomaterials based on chitin and chitosan in wound dressing applications. Biotechnol Adv 2011; 29: 322-337.

21. Depan D, Surya PKCV, Girase B, et al. Organic/inorganic hybrid network structure nanocomposite scaffolds based on grafted chitosan for tissue engineering. Acta Biomater 2011; 7: 2163-2175. 
Journal of Elastomers and Plastics, 2017, 50(5): 419-434. DOI: $\underline{10.1177 / 0095244317729578}$

22. Muzzarelli RAA. Chitosan composites with inorganics, morphogenetic proteins and stem cells, for bone regeneration. Carbohydr Polym 2011; 83: 1433-1445.

23. Mei L, Hu D, Ma J, et al. Preparation, characterization and evaluation of chitosan macroporous for potential application in skin tissue engineering. Int J Biol Macromol 2012; 51: 992-997.

24. Mahmoud AA and Salama AH. Norfloxacin-loaded collagen/chitosan scaffolds for skin reconstruction: preparation, evaluation and in-vivo wound healing assessment. Eur $J$ Pharm Sci 2016; 83: 155-165.

25. Bhardwaj N, Nguyen QT, Chen AC, et al. Potential of 3-D tissue constructs engineered from bovine chondrocytes/silk fibroin-chitosan for in vitro cartilage tissue engineering. Biomaterials 2011; 32: 5773-5781.

26. Suh JKF and Matthew HWT. Application of chitosan-based polysaccharide biomaterials in cartilage tissue engineering: a review. Biomaterials 2000; 21: 2589-2598

27. Ganji F and Abdekhodaie MJ. Chitosan-g-PLGA copolymer as a thermosensitive membrane. Carbohydr Polym 2010; 80: 740-746.

28. Chen Y, Zhang Y, Wang F, et al. Preparation of porous carboxymethyl chitosan grafted poly (Acrylic acid) superabsorbent by solvent precipitation and its application as a hemostatic wound dressing. Mater Sci Eng C Mater Biol Appl 2016; 63: 18-29. 
Journal of Elastomers and Plastics, 2017, 50(5): 419-434. DOI: $\underline{10.1177 / 0095244317729578}$

29. Valero MF, Pulido JE, Ramírez Á, et al. Determinación de la densidad de entrecruzamiento de poliuretanos obtenidos a partir de aceite de ricino modificado por transesterificación. Polímeros 2009; 19: 14-21.

30. Valero MF, Pulido JE, Ramírez Á, et al. Sintesis de poliuretanos a partir de polioles obtenidos a partir del aceite de higuerilla modificado por transesterificación con pentaeritritol. Quim Nova 2008; 31: 2076-2082.

31. Szycher M. Szycher's handbook of PUs. Boca Raton, FL: CRC Press, 2013.

32. Scheinmann F. Nuclear magnetic resonance and infrared spectroscopy. In: Scheinmann F (ed) An introduction to spectroscopic methods for the identification of organic compounds. Minnesota: Pergamon Press, 1970, pp.201.

33. Valero MF and Díaz LE. Bioadhesive PU obtained from polyols derived of CO and starch modified candidates in biomedical applications. Rev Latinoam Metal y Mater 2016; 36: 9-19.

34. Martínez-Camacho A.P, Cortez-Rocha MO, Ezquerra-Brauer JM, et al. Chitosan composite films: thermal, structural, mechanical and antifungal properties. Carbohydr Polym 2010; 82: 305-315.

35. Zhang M, Pan H, Zhang L, et al. Study of the mechanical, thermal properties and flame retardancy of rigid PU foams prepared from modified castor-oil-based polyols. Ind Crops Prod 2014; 59: 135-143. 
Journal of Elastomers and Plastics, 2017, 50(5): 419-434. DOI: $\underline{10.1177 / 0095244317729578}$

36. Temenoff JS and Mikos AG. Biomaterials, the intersection of biology and materials science. London: Pearson/Prentice Hall, 2008, p.478.

37. Zia KM, Qureshi NA, Mujahid M, et al. Chitin based PUs using hydroxyl terminated polybutadiene, Part II: morphological studies. Int J Biol Macromol 2013; 59: 313-319.

38. Baheiraei N, Yeganeh H, Ai J, et al. Synthesis, characterization and antioxidant activity of a novel electroactive and biodegradable polyurethane for cardiac tissue engineering application. Mater Sci Eng C 2014; 44: 24-37.

39. Arevalo F, Uscategui YL, Diaz L, et al. Effect of the incorporation of chitosan on the physico-chemical, mechanical properties and biological activity on a mixture of polycaprolactone and polyurethanes obtained from castor oil. J Biomater Appl 2016; 31: $708-720$. 